\title{
Liquid Nitriding of Stainless Steel 316L to Improve Fatigue Properties for Orthopedic Screws
}

\author{
Marwan N. Arbilei \\ Jamal Mohammed Hamed \\ Biomedical Eng. Dep., University of Technolog, Baghdad, IRAQ \\ engmna@gmail.com \\ jamal_hamed2001@yahoo.com
}

\author{
Received: 30-May-2018 \\ http://doi.org/10.29194/NJES.21040508
}

\begin{abstract}
Liquid nitrate is an important method used to improve mechanical properties, one of these properties is resistance to fatigue. The aim of this study was to improve the fatigue resistance of the stainless steel $316 \mathrm{~L}$. The rotational bending method was used with constant and variable stresses at different times of $(1,3,5)$ hours and at $(530,630){ }^{\circ} \mathrm{C}$. These tests were performed before and after nitration.

The results showed that the depth of the nitride layer was $(0.21,0.33,0.45) \mathrm{mm}$, increasing with time nitriding when the temperature was $530{ }^{\circ} \mathrm{C}$. While the depth of this layer at a temperature of $630{ }^{\circ} \mathrm{C}(0.26,0.39,0.5) \mathrm{mm}$ with increasing time. As a result of these processes, a layer of solid chromium nitrides and other phases of iron nitride were formed on the outer surface. These layers helped to inhibit the growth of the cracks and their progress in addition to the generation of pressure stresses on the surface leading to obstructing the progress of the cracks.

This study showed that the fatigue resistance was directly proportional to the increase in nitrate time due to the increased depth of the hardened layer, but this resistance decreased when the temperature was $630{ }^{\circ} \mathrm{C}$ due to the formation of brittle phase with low resistance.
\end{abstract}

Keywords: Liquid Nitriding, SS316L, Fatigue, Brinell Hardness.

\section{Introduction:}

Austenitic stainless steels stainless 316L are used in different industrial extremely corrosive and biomedical applications. These soft steels have low hardness and wear protection resistance. Accordingly, their application is limited. Surface Engineering applied by many researchers by adjusting material's surface to enhance surface properties to improve the surface contact with the atmosphere. This enhanced their erosion protection and strength in addition to their ability to provide appropriate properties at economic cost on a production scale $[1,3]$.

In the past decades, high nitrogen steels (HNS) have been regarded as substitutes for conventional austenitic stainless steels because of their superior mechanical and corrosion properties. However, the main limitation to their wider application is their expensive production processes. As an alternative, high temperature solution nitriding has been applied to produce HNS from three commercially available stainless-steel grades (AISI 304L, AISI 316 and EN 1.4369) [4]. As for the powder metallurgy process, the dissolution of nitrogen occurs in the solid state, where the solubility is higher [5].

Since the middle of the 80 s, low temperature thermochemical treatments have been developed for surface hardening of austenitic stainless steels, including gas carburizing and plasma nitriding. These processes can induce formation of a precipitate-free interstitially supersaturated metastable expanded austenite, also known as Sphase, having superior hardness and improved wear resistance, while maintaining corrosion resistance [6].

Liquid nitriding of austenite stainless 321 steel was conducted at low temperature of $430{ }^{\circ} \mathrm{C}$, using a type of a complex chemical heat-treatment; and the properties of the nitride surface were evaluated. Experimental results revealed that a modified layer was formed on the surface with the thickness ranging from 2 to $30 \mu \mathrm{m}$ varying with changing treatment time. When the stainless steel subjected to the advanced liquid nitriding less than $8 \mathrm{~h}$ at 430 ${ }^{\circ} \mathrm{C}$, the main phase of the nitride coating layer was the $S$ phase generally. When the treatment time prolonged up to $16 \mathrm{~h}, \mathrm{~S}$ phase formed and partially transformed to $\mathrm{CrN}$ subsequently; and then the fine secondary CrN phase precipitated [7].

Compared to conventional gas nitriding and ion nitriding, the liquid nitriding treatment (salt bath nitriding) was regarded as an effective, lowcost method with many advantages, such as low treatment temperature, short treatment time, high degree of shape and dimensional stabilities, and reproducibility [8].

Nitriding Enhancements gained through plasma nitriding without affecting their corrosion resistance. Where, this method applied in temperature range from $(350-570){ }^{\circ} \mathrm{C}$ for two hours. The different types of nitrides which formed improved the microhardness, which improved microwear behavior and the corrosion resistance [9]. 
Liquid nitriding applied in a range of temperatures between $(400-670){ }^{\circ} \mathrm{C}$ for carbon steel $\mathrm{C} 110$. The nitride layer depth increased significantly with increasing the treating temperature. The liquid nitriding effectively improved the surface hardness and dependently tensile strength also. After liquid nitriding, the absorption energy of the treated sample decreased. In addition to elongation decreasing. Despite of treatment temperature, the liquid nitriding can improve the corrosion [10].

The fatigue strength was improved by the plasma nitriding and the shape of the $\mathrm{S}-\mathrm{N}$ curves was a asymptote shape with a fatigue limit up to $\mathrm{N}$ $=108$ cycles. The fatigue cracks initiated from specimen surface in all specimen. However, the improvement of fatigue strength by plasma nitriding and the influence of nitriding time on the fatigue strength was small because the nitriding layer was quite thin, it is believed that the nitride layer could not affect significantly the fatigue strength. [11] meanwhile the fatigue behavior of EN8 steel under different treatments such as coating, nitriding, induction hardening and combined nitriding and induction hardening. The EN8 steel was exposed to Nitriding in cyanide salt bath with $560^{\circ} \mathrm{C}$. Results showed that coating on nitride specimens produces high fatigue resistance [12].

According to above review it could be concluded that the nitriding was conducted with different ways to investigate its effect on different mechanical properties. Meanwhile, only plasma nitriding has been used to study it effect on fatigue property. In this work liquids nitriding will be applied to investigate the effect of fatigue properties.

\section{Experimental Part: \\ 1. Materials:}

The alloy used in this study is $316 \mathrm{~L}$ steel with chemical composition shown in Table (1). These samples received as a rod with a diameter of 10 mm. The Mechanical Properties of these samples also illustrated in Table (2).

Table (1) The Chemical Composition of 316 Stainless steel rods as received from Provider according to data sheets that supplied in the provider website

\begin{tabular}{|c|c|c|c|c|c|c|c|}
\hline $\mathbf{C}$ & $\mathbf{S i}$ & $\mathbf{M n}$ & $\mathbf{P}$ & $\mathbf{S}$ & $\mathbf{C r}$ & $\mathbf{M o}$ & $\mathbf{N i}$ \\
\hline 0.03 & 0.73 & 1.9 & 0.044 & 0.03 & 16.8 & 2.6 & 11.3 \\
\hline
\end{tabular}

Table (2) mechanical properties of 316 Stainless steel rods as received from Provider according to data sheets that supplied in the provider website.

\begin{tabular}{|c|c|c|c|}
\hline $\begin{array}{c}\text { UTS } \\
\text { (MPa) }\end{array}$ & $\begin{array}{c}\text { 0.2\% YS } \\
\text { (MPa) }\end{array}$ & Elongation \% & HB \\
\hline 480 & 175 & 42 & 210 \\
\hline
\end{tabular}

\section{Experimental Procedure:}

The Stainless-Steel rods operated on a CNC lathe to obtain high accuracy fatigue samples. The sample surfaces were then smoothed to eliminate the stress concentration areas. Standard E-8 dimensions of the sample used in rotational bending tests. As shown in Figure (1).

After preparing the fatigue samples, all samples were thermally treated by quenching treatment to obtain a solid heart and a hard surface. This heat treatment included heating the samples to a temperature of $980{ }^{\circ} \mathrm{C}$ and fixed at this degree for one hour after that quenched in oil.

Tempering Treatment applied at a temperature of $600{ }^{\circ} \mathrm{C}$ for one hour and then air cooled. This treatment procedure explained in Figure (2)

Liquid Nitriding was carried out in molten salt baths. Before nitriding the samples were placed in oven at a temperature of $120^{\circ} \mathrm{C}$ for 30 minutes for the purpose of release the dirt and oil. The samples were then cleaned in special containers and placed in the furnace for the nitrate, after the furnace was heated to $530 \mathrm{C}^{0}$ for 1 hour. The above treatment was repeated on other samples of the same steel but for 3 hours and then for 5 hours. The samples were removed from the furnace and cooling in air. The nitride thermal treatment was then performed on other samples and at the same previous time periods but at a temperature of $630^{\circ} \mathrm{C}$.

The rotating bending fatigue tester $\mathrm{Hi}$-Tech shown in Figure (3) have been used to investigate the fatigue life time.

Grinding and polishing operations were performed to all the samples in order to investigate the macro hardness. Brinell Macro-Hardness measurements have been done using prufmas chinen 3030 rating device. Five readings were taken and the average of these five readings was concluded, to measure microscopic hardness at successive depths of the sample surface. 


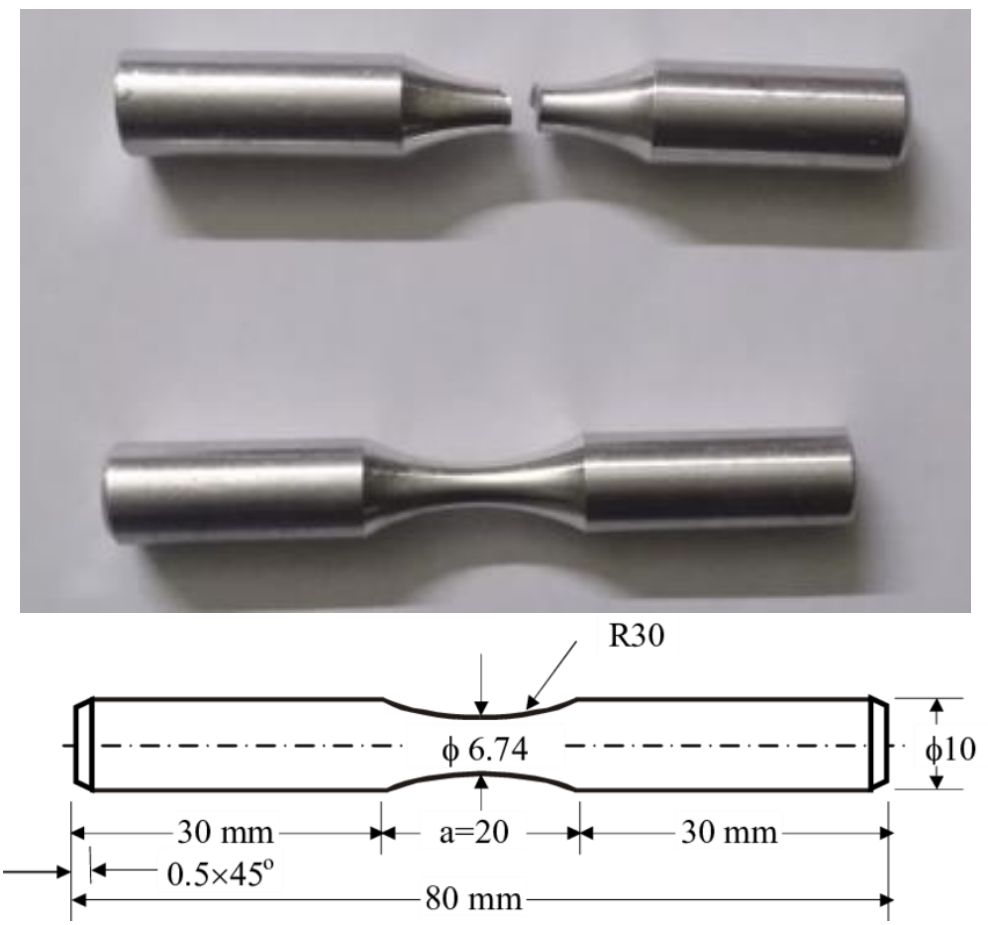

Figure (1) Standard Fatigue Specimen Dimensions
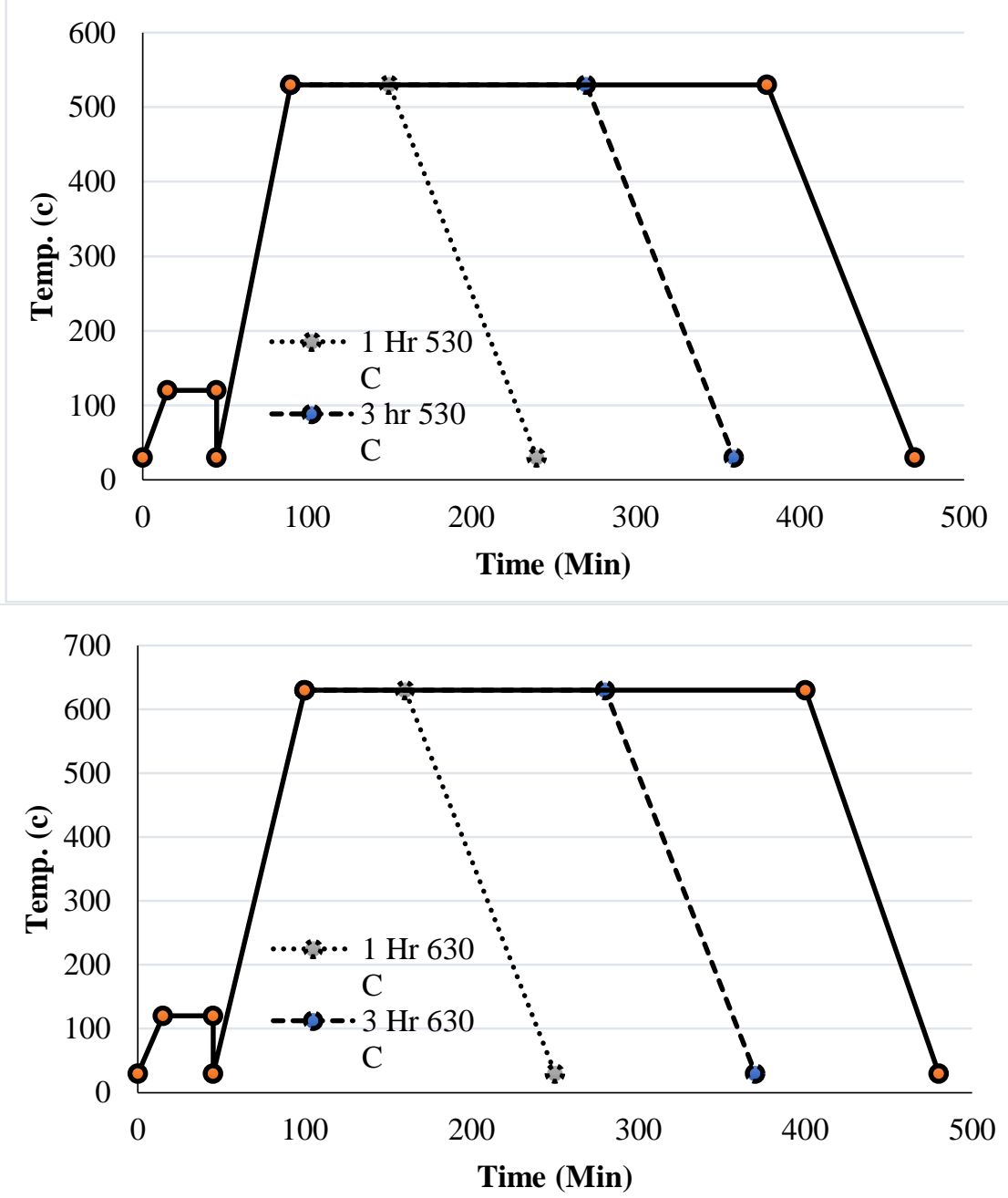

Figure (2) Heat Treatment Plans of Nitriding with three times (1,3 and 5 Hrs) with two different Temperatures (530 and 630) $\mathrm{C}^{\circ}$ 


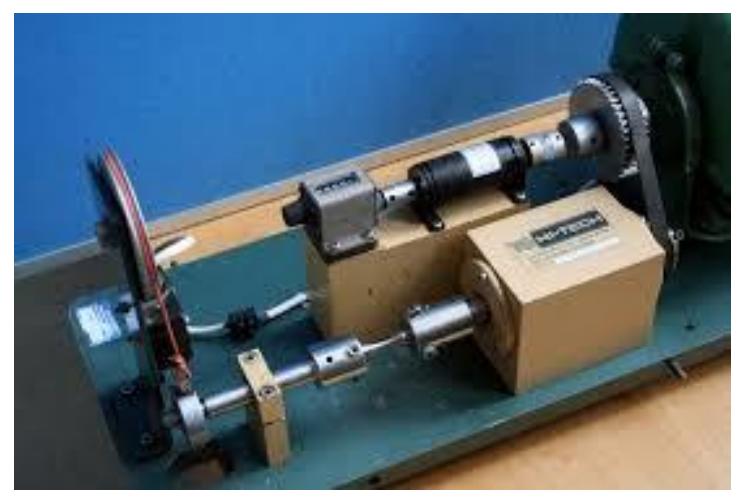

Figure (3) Fatigue test device

\section{Results}

The hardness - distance plots shown in Figure (4.A and 4.B) showed that the hardness increased with nitriding time meanwhile the depth of layer remains the same. This showed that the nitrided was slightly increased with temperature and not effected with time.

The two sets of samples that have been nitrided with (530 and 630) $\mathrm{C}^{\mathrm{o}}$ with the three times have been investigated by Brinell Hardness along $1 \mathrm{~mm}$ from outer surface towards the center of samples. The reads that illustrated in Table (3) shows the hardness values variation with distance.

According to this result, it was clearly seen that the fatigue resistance also increased with hardness values. As shown in Figure (5.A 5. B and 5.C). and the variation in fatigue limit stress was more clearly increased with treatment time as shown in Table (4). These results compared with annealed
Samples to indicated the effect of nitriding far from annealing process that have been done. The depth of the hardened layer did not change according to the drawing, but the value of the fatigue increased with time due to the increase in the value of the hardness and not the depth and thus affect the initiation and propagation of crack while the depth affects the progress of this crack.

Variable load: Study of the effect of the change in the capacity of the fatigue stress at the age of samples of different nitrate time.

Figure (6) showed the loading program (lowhigh, high-low). The nitrification process showed that the samples were older than four, five and seven times respectively at recessive times $(1,3,5)$ (Low to high). At high loading, the increase in ages was three, four, and six times respectively at receding times $(1,3,5)$. This is because the cracks grow and appear faster at loading (high-low).

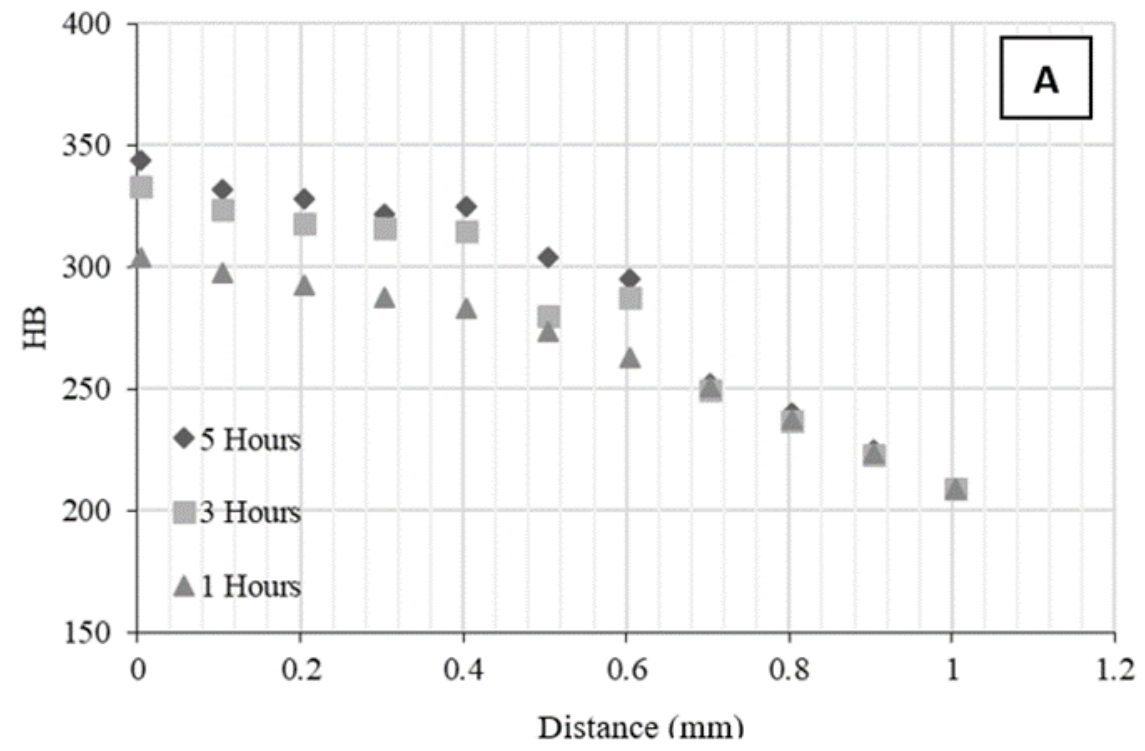




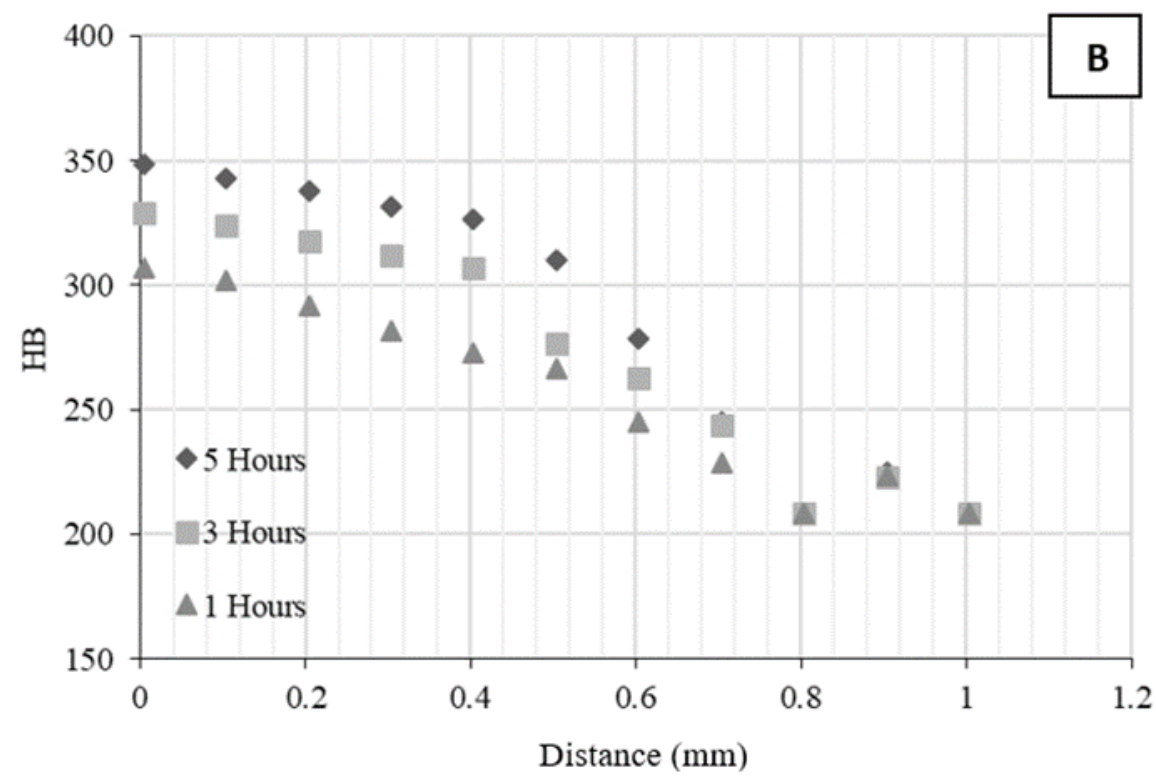

Figure (4) The relationship between the brinell hardness and distance from the surface of the Nitrided Samples for 1,3 and 5 hours at $\mathbf{A}: 530 \mathrm{C}^{0}$ and $\mathbf{B}: 630 \mathbf{C}^{0}$

Table (3) Brinell hardness Values along the distance from surface to core for nitrate samples at 530 and 630 $\mathrm{C}^{0}$ for 1,3 and 5 Hours

\begin{tabular}{|c|c|c|c|c|c|c|}
\hline \multirow{2}{*}{$\begin{array}{l}\text { Distance } \\
\text { (mm) }\end{array}$} & \multicolumn{3}{|c|}{$\mathrm{HB}$ for nitride Samples at $630^{\circ} \mathrm{C}$} & \multicolumn{3}{|c|}{$\mathrm{HB}$ for nitride Samples at $530^{\circ} \mathrm{C}$} \\
\hline & \begin{tabular}{|c|}
1 Hour \\
\end{tabular} & 3 Hours & 5 Hours & 1 Hour & 3 Hours & 5 Hours \\
\hline 0 & 305 & 334 & 345 & 308 & 330 & 350 \\
\hline 0.1 & 299 & 325 & 333 & 303 & 325 & 344 \\
\hline 0.2 & 294 & 319 & 329 & 293 & 319 & 339 \\
\hline 0.3 & 289 & 317 & 323 & 283 & 313 & 333 \\
\hline 0.4 & 284 & 316 & 326 & 274 & 308 & 328 \\
\hline 0.5 & 275 & 281 & 305 & 268 & 278 & 311 \\
\hline 0.6 & 264 & 289 & 296 & 246 & 264 & 280 \\
\hline 0.7 & 252 & 251 & 253 & 230 & 245 & 246 \\
\hline 0.8 & 239 & 238 & 241 & 210 & 210 & 210 \\
\hline 0.9 & 225 & 224 & 226 & 225 & 224 & 226 \\
\hline 1 & 210 & 210 & 210 & 210 & 210 & 210 \\
\hline
\end{tabular}

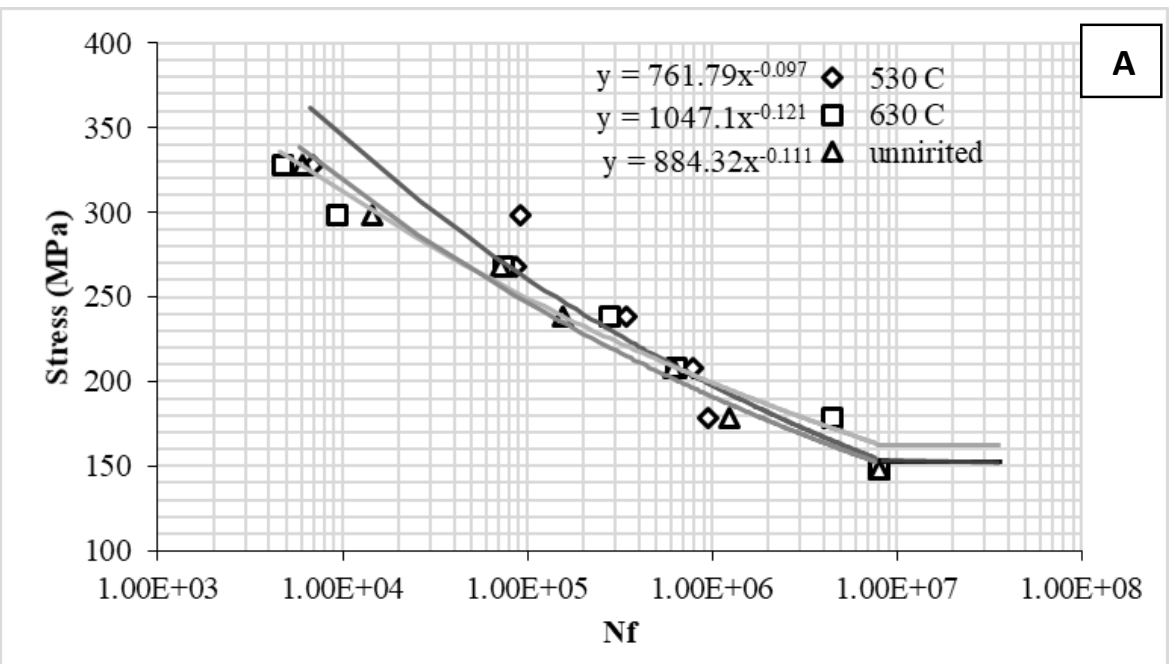




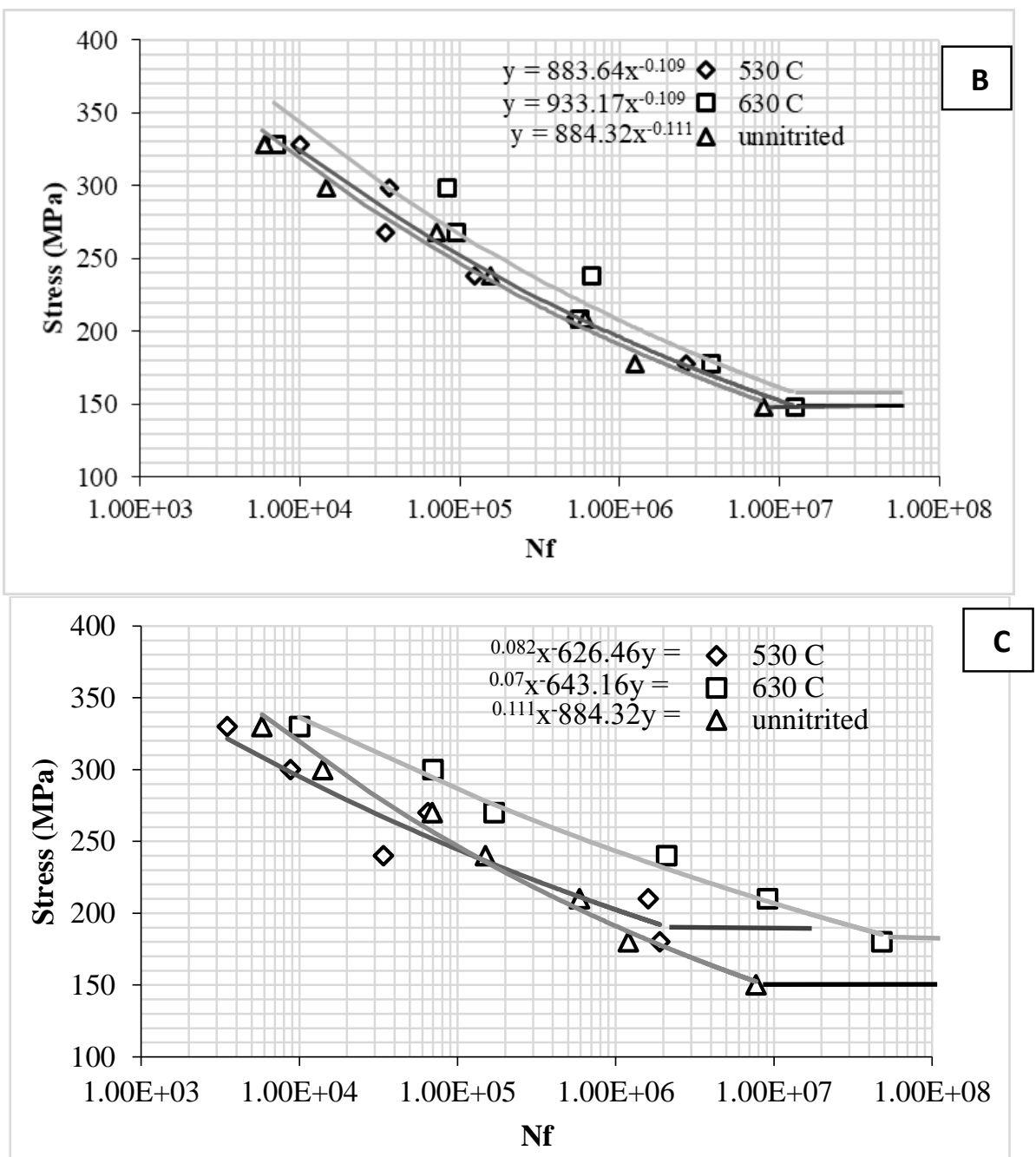

Figure (5) The S-N Curves for the un-nitritede Samples with Nitrited Samples at $530 \mathrm{C}^{0}$ and $630 \mathrm{C}^{0}$ for $\mathbf{A}: 1$ Hour, B:3Hours and C:5 Hours

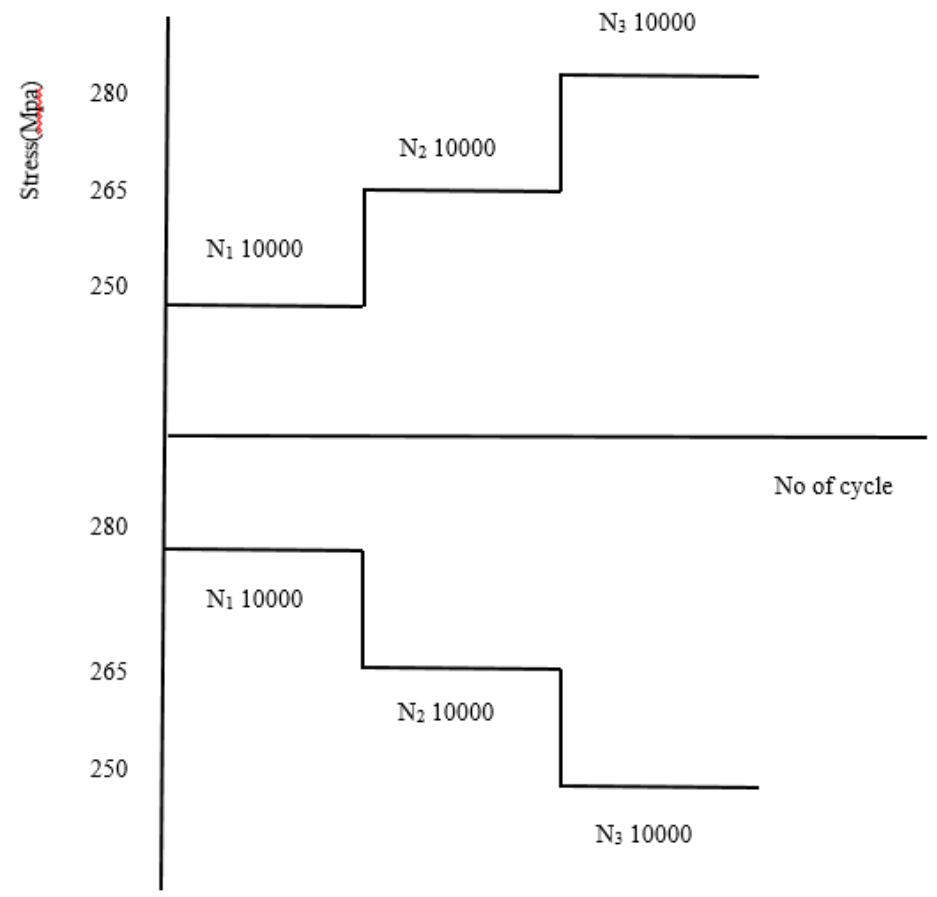

Figure (6): Load program (low-high) at (250-280) Mpa and (high-low) at (280-250) Mpa at Ns $=10000$ 
Table (4) The Relationship Between Fatigue Life and Nitriding Time at Different Temperatures

\begin{tabular}{|c|c|c|}
\hline \multirow{2}{*}{$\begin{array}{c}\text { Nitriding Time } \\
\text { (Hours) }\end{array}$} & \multicolumn{2}{|c|}{ Fatigue Limit (MPa) } \\
\cline { 2 - 3 } $\mathbf{6 3 0}^{\circ} \mathbf{C}$ & $\mathbf{5 3 0}^{\circ} \mathbf{C}$ \\
\hline 1 & 156 & 160 \\
\hline 3 & 160 & 165 \\
\hline 5 & 185 & 190 \\
\hline
\end{tabular}

Table (5) The results of examination of the accumulated damage in the samples that were nitriding at different time at $530 \mathrm{C}^{0}$

\begin{tabular}{|c|c|c|c|}
\hline $\begin{array}{c}\text { Loading } \\
\text { Sequence }\end{array}$ & $\begin{array}{c}\text { Stress } \\
\text { (MPa) }\end{array}$ & $\mathbf{N}_{\mathbf{s}}$ & $\mathbf{N}_{\mathbf{f}}$ \\
\hline \multicolumn{5}{|c|}{ Without Nitriding } \\
\hline $\mathrm{L}-\mathrm{H}$ & $250-280$ & 10000 & 195443 \\
\hline $\mathrm{H}-\mathrm{L}$ & $280-250$ & 10000 & 244600 \\
\hline \multicolumn{5}{|c|}{ Nitriding For 1 Hour } \\
\hline $\mathrm{L}-\mathrm{H}$ & $250-280$ & 10000 & 295300 \\
\hline $\mathrm{H}-\mathrm{L}$ & $280-250$ & 10000 & 414542 \\
\hline \multicolumn{5}{|c|}{ Nitriding for 3 Hours } \\
\hline $\mathrm{L}-\mathrm{H}$ & $250-280$ & 10000 & 495830 \\
\hline $\mathrm{H}-\mathrm{L}$ & $280-250$ & 10000 & 799901 \\
\hline \multicolumn{5}{|c|}{ Nitriding for 5 Hours } \\
\hline $\mathrm{L}-\mathrm{H}$ & $250-280$ & 10000 & 891223 \\
\hline $\mathrm{H}-\mathrm{L}$ & $280-250$ & 10000 & 1666570 \\
\hline
\end{tabular}

\section{Discussion:}

This study showed that the depth of the nitride layer increases with the increased duration of the nitride process at constant temperature. The depth of the nitride layer was $0.21 \mathrm{~mm}$ when the nitrate time was $1 \mathrm{hr}, 0.33 \mathrm{~mm}$ at $3 \mathrm{hr}$ and $0.45 \mathrm{~mm}$ at 5 hr when the temperature was $530 \mathrm{C}^{0}$.

Note that the higher depth of the nitride layer, the faster spread of the hydrogen atoms, making it difficult to reach deep ranges of nitrate. When the nitride process was performed at $630 \mathrm{C}^{0}$ and the same previous time intervals 1,3 , and $5 \mathrm{hr}$, the depth of the nitride layer was found to be 0.26 , $0.39,0.5 \mathrm{~mm}$ respectively. When comparing the results between the two cases it was observed that the depth of the nitride layer was greater when the process at $630 \mathrm{C}^{0}$, this could be due to the presence of some elemental alloys such as phosphorus and sulfur led to the formation of brittle phases, which the decrease of hardness values as a approved by previse studies $[4,7,8]$.

The primary purpose of thermal treatment prior to the nitride process was to obtain a solid heart and a hard surface and this condition was not affected by nitrate processes. The results of this work showed that the best fatigue life and hardness values could be resulted with higher temperatures at which the nitrate processes are (650) $\mathrm{C}^{0}$ and this depends on the method of nitride that will be conducted whether gas or liquid or solid [10,12].

The fatigue limit increased after the nitrate process and the value of this increase was proportional to nitrate time. This increase was due to the formation of hard chromium nitrides on the surface of the steel which will work agenst crack initiation and propagation.

Finally, when variable cyclic stresses are applied, the age of fatigue is higher at loading (high - low) compared to the loading (low - high), when these samples are with nitride or without it. This is due to the presence of a ductile zone in the top of crack that prevents these cracks from advancing.

\section{Conclusions:}

1- The age of the fatigue is increased as the nitrate process increases, the nitrate process at $530 \mathrm{C}^{0}$ is better than $630 \mathrm{C}^{0}$

2- Increase the depth of the hard layer with increasing time of the nitride process.

3- Increasing the temperature to more than $650 \mathrm{C}^{0}$ leads to a reduction in the threshold of fatigue. this depends on the method of nitride that will be conducted whether gas or liquid or solid $[10,12]$.

4- The age of fatigue is greater when loading (high - low) compared to loading (low - high), because the presence of a ductile zone in the top of crack that prevents these cracks from advancing.

\section{References}

1- P.Elango," A Review Paper on Methods of Improvement of Wear, Corrosion and Hardness Properties of Austenitic Stainless steel 316L",December 2014 ,International Journal of Engineering Research and Reviews, Vol. 2, , Issue 4, pp: (18-23).

2- Aryan Singh, "Hardness, Wear and Corrosion Improvement techniques for Austenitic Stainless Steel SS316L - A Review", International Research Journal of Engineering and Technology (IRJET), 2017, Volume: 04 Issue: 10 Page 955

3- S.P Ayodeji, T.E Abioye and S.O Olanrewaju, "Investigation of Surface Hardness of Steels in Cyanide Salt Bath Heat Treatment Process", 2011, Proceeding of Conference of Engineering and computer sciences. VOL. 2

4- Bottoli, F., Winther, G., Christiansen, T. L., Dahl, K. V., \& Somers, M. A. J. (2016). LowTemperature Nitriding of Deformed Austenitic Stainless Steels with Various Nitrogen Contents Obtained by Prior High-Temperature Solution Nitriding. Metallurgical and Materials Transactions A: Physical Metallurgy and Materials Science, 47(8),4146-4159. DOI: 10.1007/s11661-016-3559-7

5- Federico Bottoli. PHD thesis (2015) "Influence of steel composition and plastic deformation on the surface properties induced by low temperature thermochemical processing" Technical University of Denmark. 
6- Giulio Maistro. PHD thesis (2018) "Low temperature carburizing/nitriding of austenitic stainless steel" Chalmers University of Technology, Gothenburg, Sweden.

7- Yuanhua. L, Jun. W, Dezhi. Z, Runbo. H, Hongyuan. F. (2013) “Advance complex liquid nitriding of stainless steel AISI 321 surface at $430 \mathrm{C}^{0}$ " Journal of materials engineering and performance. DOI: 10-1007/s11665-013-05458.

8- Y.Z. Shen, K.H. Oh, D.N. Lee (2005) "Nitriding of steel in potassium nitrate salt bath" School of materials science and engineering, Seoul National University, Shinrim-dong, Gwanak-gu, Seoul 171-744, Republic of Korea.

9- Joaquim.O.P, Raphael. O.S, Edilaine. H.S, Jeferson.A. (2016) "Wear and corrosion study of plasma nitriding F53 super duplex stainless steel" Materials research 2016:19(6):12411252. DOI: 10.1590/1980-5373-MR-20150656.

10- Jing Yan, Jun Wang, Tan Gu, (2017) "Effect of liquid nitriding at $400-670 \mathrm{C}^{0}$ on microstructure and properties of C110 steel" Journal of central south university Feb 2017, vol 24, issue2, pp 325-334.

11-Daisuke Yonekura, K.Ozaki, R. Shibahara (2013) "Very high cyclic fatigue behavior of plasma nitrided 316 stainless steel" 13 International conference on fracture June 1621-2013 Beijing, china.

12-Senthil Kumar, S. Ragunathan, M.Suresh (2016) "Influence of different surface treatments on fatigue behavior of EN8 steel" ISSN:1995-0772. EISSN:1998-1090. 2016 special 10(7): pages 326-341.

\section{النيتروجين السائل من الفو لاذ المقاوم للصدأ L316 لتحسين خاصية الإعياء لمسامير العظام}

قروان نافع الطبي الحياتي ـ الجامعة التكنولوجية، بغداد، العمراق حمد

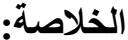

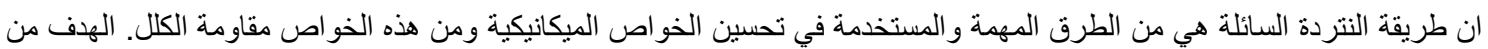

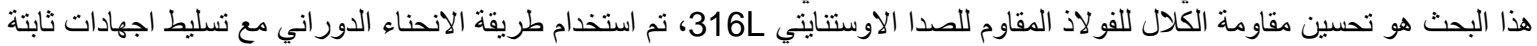

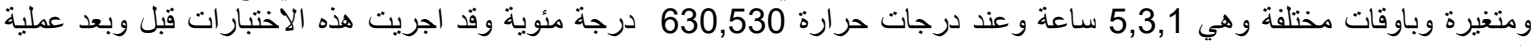

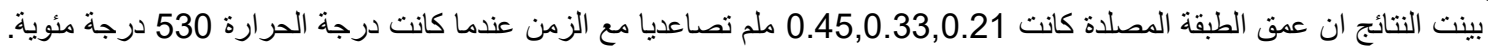

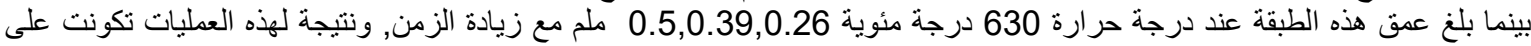

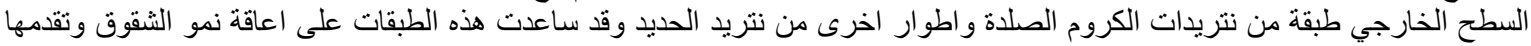

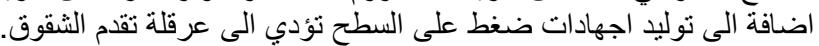

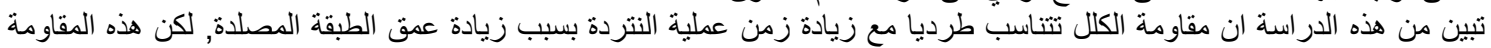

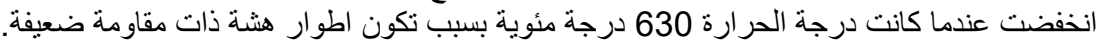

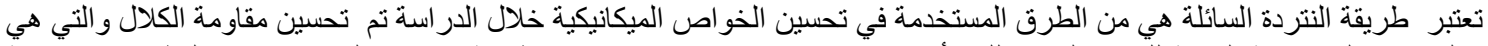

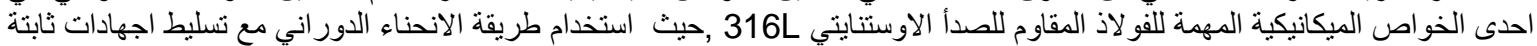

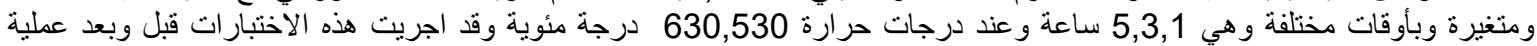

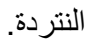

من خلال النتائج تبين ان عمق الطبقة المصلدة كانت

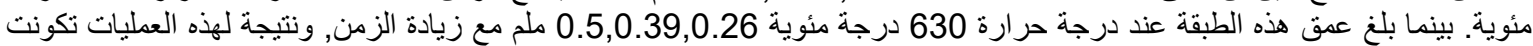

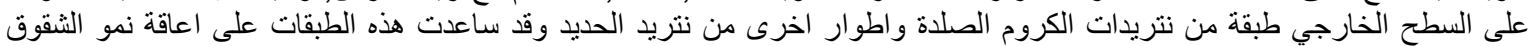

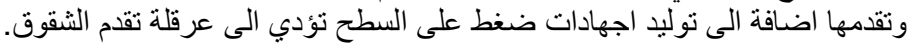

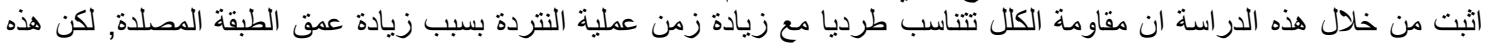

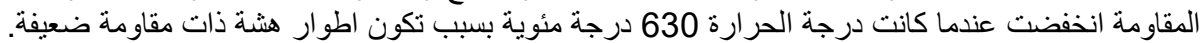

